\title{
LOGISTICA REVERSA E O PROCESSO DE DESTINAÇÃO DAS EMBALAGENS VAZIAS DE AGROTÓXICO
}

Melissa Martin de OLIVEIRA ${ }^{1}$

Débora Zumkeller SABONARO²

\author{
${ }^{1}$ Graduanda em Engenharia Ambiental pela Universidade de Sorocaba. melfmartin20@gmail.com \\ ${ }^{2}$ Professora e Pesquisadora da Universidade de Sorocaba dzsabonaro@hotmail.com
}

Recebido em: 16/12/2015 - Aprovado em: 13/07/2016 - Disponibilizado em: 18/12/2016

\begin{abstract}
RESUMO:
O presente trabalho tem por principal objetivo destacar a importância da destinação final adequada para as embalagens vazias de agrotóxicos visando a saúde da população e a proteção ao meio ambiente. Trata-se de um estudo bibliográfico e de uma pesquisa de campo aplicada a unidade de recebimento de embalagens vazias de agrotóxico situada na cidade de Piedade. Foi realizada a observação dos procedimentos para destinação final, o número de embalagens desenvolvidas, o local de origem e de destino desse material e formas de aproveitamento das embalagens.

Palavras Chave: Logística reversa. Agrotóxicos. Educação Ambiental. Impacto Ambiental. Impacto a Saúde Humana e
\end{abstract} Animal.

\begin{abstract}
This course conclusion work is primarily to highlight the importance of proper disposal for the empty pesticide containers aimed at the population's health and environmental protection. This is a bibliographic study and field research applied to receiving unit empty containers of pesticides in the city of Piedade. Observing the procedures for final disposal will be made, the number of developed packaging, place of origin and destination of the material and forms of use of packaging.

Keywords : Reverse logistics. Pesticides. Environmental education. Environmental impact , Impact human health and Animals.
\end{abstract}

\section{INTRODUÇÃO}

Com a evolução da sociedade e das tecnologias houve um grande aumento da produção de produtos industrializados. Com a revolução industrial que teve início no século XVIII houve uma grande mudança na sociedade especialmente em relação ao consumo, consequentemente veio o aumento da geração dos resíduos sólidos.

Não se pode negar a facilidade e a qualidade de vida que acarretou a revolução industrial, porem a sociedade e o meio ambiente vivem em um intenso processo dinâmico, pois os fatores consumo e o aumento dos resíduos, afetam ao meio ambiente causando impactos ambientais expressivos a sociedade, como a contaminação dos lençóis freáticos, contaminação dos solos e a disseminação de doenças.

Isso tudo se dá pela forma que esses resíduos são depositados inadequadamente em locais que não estão preparados para 
receber alguns tipos de produtos, como os resíduos tecnológicos cujos componentes podem ser agressivos ao meio ambiente.

Existe também a cultura do descartável na qual nada hoje em dia é produzido para durar por longos períodos, mas sim para serem descartados logo, dessa forma incentivando a sociedade consumir mais.

A geração de resíduos sempre existiu, desde quando o ser humano vive no planeta, porem pela quantidade e pela qualidade eram deixados na natureza que por sua vez se encarregava de reabsorvê-los.

Outro fator que contribuiu para o aumento dos resíduos foi o aumento da população. É gerado em torno de $1 \mathrm{~kg}$ per capita por dia de lixo.

Com essa situação problemática é aprovada em 02 de agosto de 2010 a Política Nacional de Resíduos Sólidos (PNRS), que firmou um marco regulatório para a gestão dos resíduos sólidos, com normas a serem seguidas, incluindo o ciclo de vida dos produtos, coleta seletiva, controle social, destinação final dos resíduos, educação ambiental e a logística reversa.

Logística reversa é um instrumento de desenvolvimento econômico e social, onde divide a responsabilidade do ciclo de vida dos produtos desde os fabricantes, importadores, distribuidores, comerciante e consumidores. Ela visa diminuir o volume e a geração de resíduos sólidos rejeitados pela população, de forma que esses materiais retornam ao fabricante na qual tem a obrigação de receber esses produtos e dar o descarte de forma adequada.

As principais substancias químicas hoje utilizadas como agrotóxicos foram desenvolvidas durante a Primeira Guerra Mundial (1914 a 1918), sendo modificas e amplamente empregadas também durante a Segunda Guerra (1939 a 1945). Após a guerra havia sobrado um grande estoque desses venenos, os químicos lembraram de que o que mata o homem poderia facilmente matar insetos. Dessa forma os venenos modernos foram modificados para serem aplicados nas lavouras (Lutzenberger, 2004).

Os agrotóxicos são os principais poluentes do modelo da agricultura atual, os venenos são aplicados em áreas determinadas porem não ficam apenas naquele determinado local. A contaminação dos recursos naturais pelo uso indevido de agrotóxicos se tornou um grave problema à saúde pública e ao meio ambiente.

Com o grande consumo de agrotóxicos surge o problema da destinação final das suas embalagens vazias, das quais podem se tornar fatores da contaminação do solo e dos recursos hídricos.

O objetivo desse trabalho é mostrar de forma clara como são desprezadas as embalagens vazias de agrotóxico. Tem por objetivo também apontar a existência de uma instituição de processamento de embalagens 
vazias (INPEV), que objetiva fiscalizar e destinar corretamente esse tipo de resíduo.

\section{METODOLOGIA}

Trata-se de um estudo bibliográfico e de uma pesquisa em campo que visa mostrar o quão preocupante é o descarte incorreto das embalagens de agrotóxico.

O levantamento de dados e informações foi realizado com base em pesquisas em postos de recebimento de embalagens vazias de agrotóxicos no município de Piedade.

Também foram feitas consultas ao site do Instituto Nacional de Processamento de Embalagens Vazias - INPEV (http://www.inpev.org.br) e as legislações em vigor Lei 7.802/89, Lei 9.974/00 e o decreto n4.074/02, do Governo Federal.

A pesquisa em campo foi executada na unidade de recebimento de embalagens vazias de agrotóxico no município de Piedade.

\section{RESULTADOS}

Nos últimos anos a quantidade de defensivos agrícolas produzidos teve uma grande procura por conta dos agricultores, no Brasil o aumento foi expressivo em relação ao mundo todo.

Os resíduos químicos tóxicos presentes em embalagens de agrotóxicos e afins, quando abandonados no ambiente ou descartados em aterros e lixões, sob ação da chuva, podem migrar para águas superficiais e subterrâneas, contaminando o solo e lençóis freáticos.

Os resíduos de embalagens de inseticidas e agrotóxicos, enquadram-se na categoria de resíduos perigosos por conterem substâncias químicas que modificam o ambiente nas suas mais diferentes formas de vida. Além disso, comprometem de forma definitiva a cadeia natural, contaminando o solo, a água e o ar e influenciado diretamente a saúde da população, seja ela de qualquer nível social. A problemática que envolve esse tipo de resíduo concentra-se na disposição pós-uso. O destino das embalagens vazias de agrotóxicos não sofria, há poucos anos atrás, nenhum tipo de fiscalização e controle, e hoje, sabe-se, que a prática de enterrá-las é considerada inadequada devido aos altos riscos de contaminação.

Há pelo menos 50 agrotóxicos que são potencialmente carcinogênicos para o ser humano. Outros efeitos são neurotoxidade retardada, lesões no Sistema Nervoso Central - SNC, redução de fertilidade, reações alérgicas, formação de catarata, evidências de mutagenicidade, lesões no fígado, efeitos teratogênicos entre outros, compõem o quadro de morbimortalidade dos expostos aos agrotóxicos.

O Instituto Nacional de Processamento de Embalagens Vazias (Inpev), entidade sem fins lucrativos responsável por recolher as 
embalagens de defensivos agrícolas e destinalas corretamente em todo o Brasil.

Foi criado após a instauração da Lei Federal de $\mathrm{n}^{\circ}$. 9.974/00, que disciplina o recolhimento e destinação final das embalagens. A Lei divide responsabilidades a todos os agentes atuantes na produção agrícola do Brasil, ou seja, agricultores, canais de distribuição, indústria e poder público.

As embalagens dos agrotóxicos utilizados geram responsabilidade ao agricultor para efetuar a devolução no prazo de 1 ano. Onde deverão receber a tríplice lavagem ou lavagem sob pressão, depois são levadas ate as lojas de agropecuária que fizeram a venda do produto, na qual encaminham para os postos, logo após são levadas as Centrais de recebimento onde são separadas, prensadas e encaminhadas para as recicladoras (não contaminadas ou laváveis) ou para incineração (embalagens contaminadas e não laváveis).

Figura 1: Embalagem não lavável e contaminada

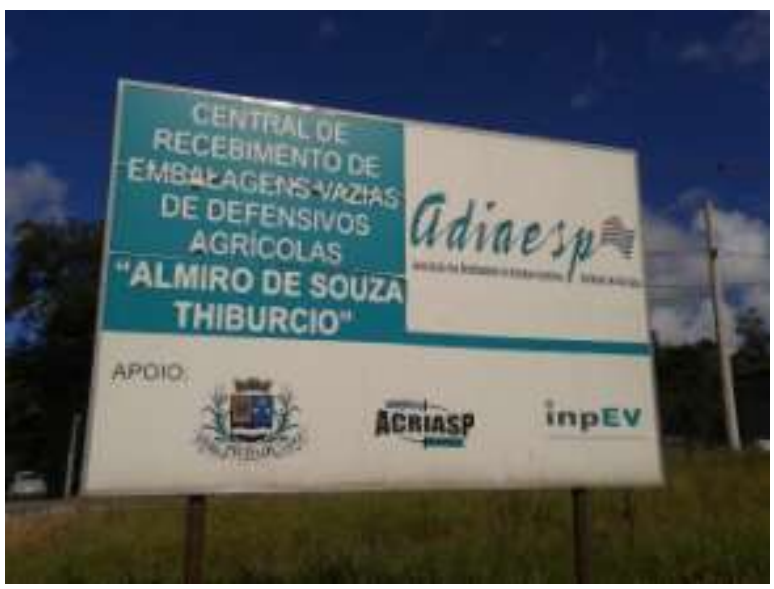

Fonte: Oliveira, 2015.
Figura 2: Embalagem Lavável

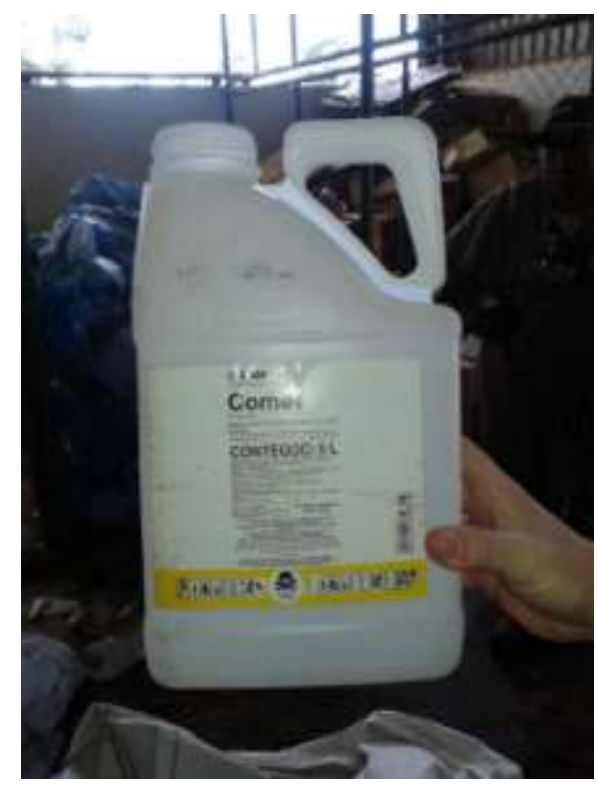

Fonte: Oliveira, 2015.

Figura 3: Central de recebimento de embalagens vazias do município de Piedade.

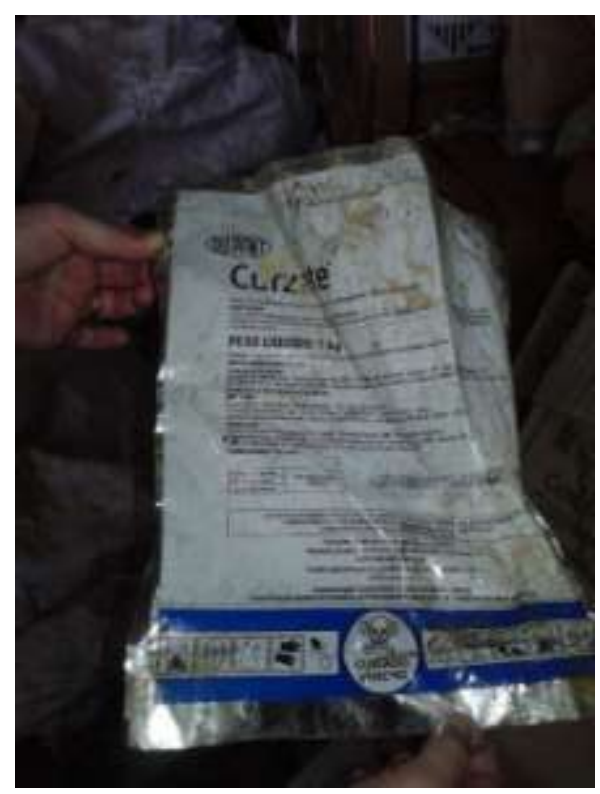

Fonte: Oliveira, 2015. 
Figura 4: Fardos de latas de aço e embalagens de PEAD não contaminadas

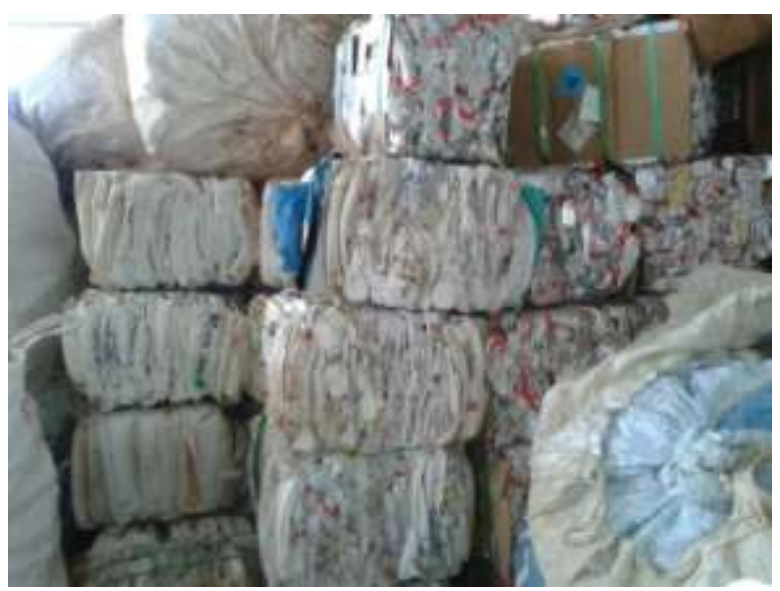

Fonte: Oliveira, M.F.M, maio 2015.

O Inpev mantém parcerias com nove empresas recicladoras, estrategicamente localizadas em cinco Estados: Mato Grosso, Minas Gerais, Paraná, Rio de Janeiro e São Paulo.

A partir da reciclagem das embalagens vazias de defensivos agrícolas, essas empresas produzem 17 diferentes produtos, em especial os de uso industrial, são eles:

\section{Recipallet}

2. Suporte para sinalização rodoviária

3. Cruzeta de poste

4. Caixa para descarga

5. Caçamba plástica para carriola

6. Caixa para massa de cimento

7. Caixa de bateria automotiva

8. Roda plástica para carriola

9. Embalagem para óleo lubrificante
10. Ecoplástica Triex

11. Barrica plástica para incineração

12. Conduite corrugado

13. Duto corrugado

14. Caixa de passagem para fios e cabos elétricos

15. Tubo para esgoto

16. Tampa agro Recicap

17. Barrica de Papelão

Figura 5: Produtos reciclados a partir das embalagens vazias.

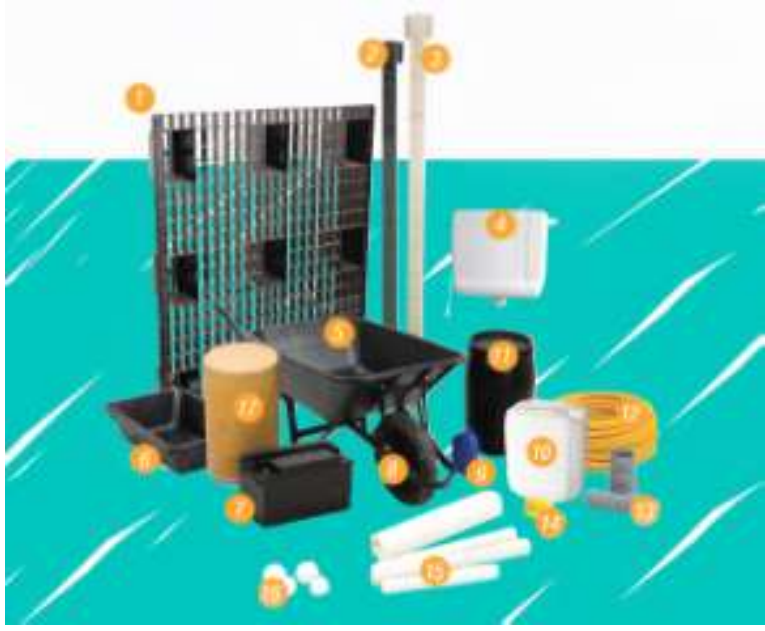

Fonte: (INPEV,2015)

O sistema de incineração das embalagens contaminadas de agrotóxicos é executado apenas pelas empresas autorizadas pelo INPEV, sendo estas ambientalmente licenciadas por órgãos ambientais competentes.

As incineradoras transformam as embalagens contaminadas em cinzas inertes e gases de natureza conhecida e ambientalmente aceitável. 
Os agricultores sem consciência e muitas vezes sem informações suficientes acabam destinando as embalagens vazias de forma incorreta sem contar 0 reaproveitamento do material para armazenagem de água e outros alimentos para consumo. O plástico por ser um material maleável e de inúmeras utilidades são vendidos para recicladoras clandestinas onde não são dados os cuidados necessários e acabam gerando problemas a saúde humana e animal. As empresas que adquirem estas embalagens ilegalmente estão cometendo um crime, pois adicionam as mesmas no processo produtivo sem nenhum controle prévio ou autorização dos órgãos competentes.

Figura 6: Criança tomando água em embalagem vazia de agrotóxico.

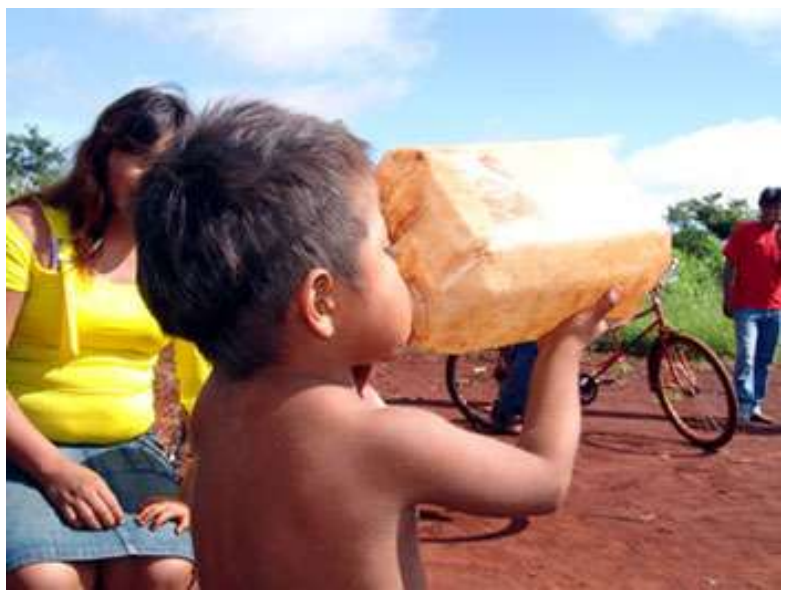

Fonte: Globo rural, 2008.
Figura 7: Vala onde são depositados ilegalmente embalagens de agrotóxico.

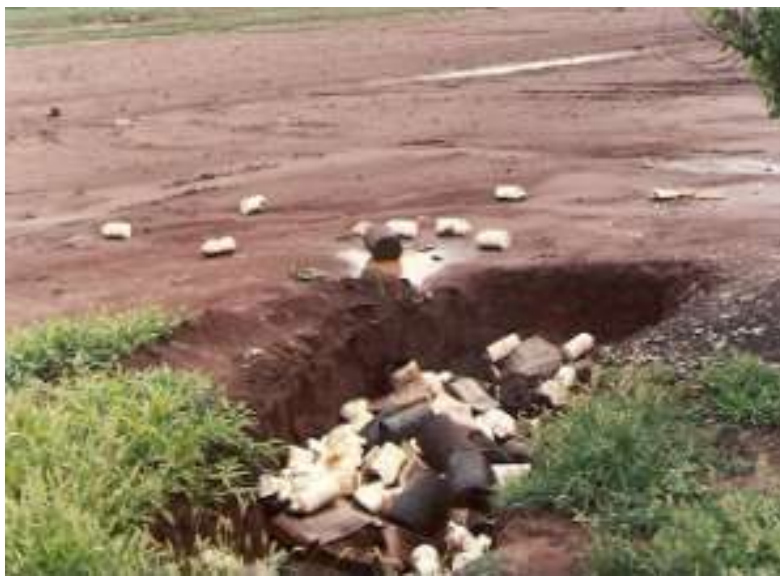

Fonte: (Globo Rural, 2008).

\section{Considerações Finais}

A reciclagem se tornou o principal conjunto de soluções para a destinação final das embalagens plásticas do mercado agrícola, as unidades de recebimentos de embalagens vazias de agrotóxicos propostos pelo INPEV e o trabalho de parceria entre todos os envolvidos no elo do sistema produtivo, forneceram o grande foco à melhor qualidade de vida, assumindo responsabilidades e desenvolvendo esforços conjuntos para o desenvolvimento agropecuário.

As leis em vigor ajudam para um melhor funcionamento da sistemática entre consumidor e meio ambiente, pois com o regresso dessas embalagens vazias para postos de recebimento e logo após o descarte final adequado, tem ajudado as populações que fazem uso desse produto químico na 
lavoura a se proteger de contaminações, dessa forma também ajudando ao meio ambiente que muitas vezes era o maior alvo de contaminação dos solos e das águas superficiais e subterrâneas.

\section{REFERÊNCIAS}

INPEV. Instituto Nacional de processamento de Embalagens Vazias, 2005. Disponível em: <http:// www.inpev.org.br> http://www.inpev.org.br/Sistemas/Estatisticas/ apresentacao-setembro-2014.pdf

NORMA REGULAMENTADORA 31 (NR 31) - Segurança e Saúde no Trabalho na Agricultura, Pecuária Silvicultura, Exploração Florestal e Aquicultura.

NORMA DA ABNT - NBR 14719, Embalagens vazia de agrotóxico - Destinação final de embalagem lavada - Procedimento.

NORMA DA ABNT - NBR 14935,

Embalagens vazia de agrotóxico - Destinação final de embalagem não lavada Procedimento.

CONSELHO NACIONAL DO MEIO AMBIENTE - CONAMA. Dispõe sobre os procedimentos de licenciamento ambiental de estabelecimentos destinados ao recebimento de embalagens vazias de agrotóxicos. Resolução n. 334, de 3 de abril de 2003. Legislação Federal.

CARSON, R. Primavera Silenciosa - 1962.

LEITE, Paulo R. - Logística Reversa: meio ambiente e competitividade - São Paulo: Pearson Prentice Hall / Pearson Education do Brasil, 2009.

RANDO, J. C. M., Diretor-Presidente do inpEV - Logística Reversa das embalagens vazias de agrotóxico. Disponível em: http://www.agroanalysis.com.br/especiais_det alhe.php?idEspecial $=88$

BARBOSA S, CAMPOS R, SILVA RC, ET

AL. Gestão de riscos à saúde coletiva e responsabilidade socioambiental. Revista de Gestão Integrada em Saúde do Trabalho e Meio Ambiente, v.4, n.3, Artigo 1, set./dez. 2009.

LYZNICKI, M. S.; et al. Educational and Information Strategies to Reduce Pesticide Risks. Preventive Medicine, Chicago, n. 26, 1997. p.191-200. 